\title{
Epidemiology of SARS-CoV-2 in Egypt
}

Ghada Nasr Radwan

${ }^{1}$ Faculty of Medicine, Cairo University, Cairo, Egypt. (Correspondence to: Ghada Nasr Radwan: ghadanasr@gmail.com).

\begin{abstract}
Background: On 30 January 2020, the World Health Organization declared the novel severe acute respiratory syndrome coronavirus-2 to be a Public Health Emergency of International Concern. Egypt is among the five countries reporting the highest number of cases in Africa.

Aims: We aimed to provide an overview of the epidemic features of COVID-19 in Egypt in order to help guide an effective lockdown-exit strategy.

Methods: The incidence proportions, case fatality rates (CFR), growth rates, doubling time (Td), basic reproductive number $\left(\mathrm{R}_{0}\right)$ and Herd Immunity Threshold (HIT) were calculated weekly and reviewed.

Results: As of 21 May 2020, the epidemic growth rate and $R_{0}$ have decreased significantly; the averages $( \pm S D)$ were 0.35 $( \pm 0.33)$ and $2.6( \pm 1.55)$ respectively. However, the incidence proportion has increased to 14 cases /100 ooo population.

Conclusion: COVID-19 transmissibility has declined but the incidence rate has increased, underscoring that any lockdown-exit strategy should include measures to strengthen physical distancing, and case-based interventions to prevent an uncontrolled upsurge of COVID-19 cases.

Keywords: COVID-19, basic reproductive number, epidemic growth rate, doubling time, case fatality rate

Citation: Radwan GN. Epidemiology of SARS-CoV-2 in Egypt. East Mediterr Health J. 2020;26(7):768-773 https://doi.org/10.26719/emhj.20.084

Received: 03/06/20; accepted: 29/06/20

Copyright ( $)$ World Health Organization (WHO) 2020. Open Access. Some rights reserved. This work is available under the CC BY-NC-SA 3.0 IGO license (https://creativecommons.org/licenses/by-nc-sa/3.o/igo)
\end{abstract}

\section{Introduction}

On 30 January 2020, the World Health Organization (WHO) declared the novel severe acute respiratory syndrome coronavirus 2 (SARS-CoV-2), which causes COVID-19, to be a Public Health Emergency of International Concern. SARS-CoV-2 is spreading from person to person primarily via direct contact or through direct droplets spread by coughing or sneezing from an infected individual (1). It has been estimated that the median incubation period of SARS-CoV-2 is 5.1 days (2) and SARS-CoV-2 patients are the main source of infection $(3,4)$. The average basic reproductive number and doubling time were estimated to be 3.28 (5) and 2.5 days (6) respectively. It has been reported that more than $80 \%$ of infected individuals are asymptomatic or show mild symptoms, $15 \%$ develop more severe symptoms, and 5\% become critically ill. The case fatality rate is estimated at $2-3 \%(7,8)$.

By 25 May 2020, 5371700 cases of COVID-19 had been reported globally, including 344815 deaths. Egypt is among the five countries reporting the highest number of cases in Africa with a total of 17265 cases as of 25 May 2020 (3). The aim of the current study is to provide an overview of the epidemic features of COVID 19 in Egypt to guide effective lockdown exit strategies.

\section{Methods}

We analyzed available data on COVID-19 cases and deaths published in the daily governmental reports (9). Data was entered on Excel and was used to plot the epidemic curves for cases and deaths. Key epidemic indicators were calculated using the following formulas $(10,11)$ :

\section{Cumulative Incidence $(\mathrm{CI})$ proportion (per 100000 population)}

$\mathrm{CI}=$ total number of cases up to certain date/ population at start of time interval (population in 1 January 2020)

Case Fatality Rate (CFR)

CFR $=$ total number of deaths up to certain date/total number of diagnosed cases up to certain date

Epidemic Growth Rate (between time 2 and time 1 ) is the rate at which the number of cases increases

$\mathrm{r}\left(\mathrm{t}_{2}-\mathrm{t}_{1}\right)=\operatorname{In}\left(\mathrm{I}_{2}\right)-\operatorname{In}\left(\mathrm{I}_{1}\right)$ (I is the cumulative incidence)

Epidemic Doubling Time (the time it takes for the incidence to double)

$\mathrm{T}_{\mathrm{d}}=\operatorname{In}(2) /[\operatorname{In}(\mathrm{I} 2)-\operatorname{In}(\mathrm{I} 1)]$

The Basic Reproductive Number $\left(R_{0}\right)$ (the expected number of secondary cases generated by one infected case)

$\mathrm{R}_{0}=1+\mathrm{rTg}$ ( $\mathrm{Tg}$ is the mean generation time/serial interval)

Herd Immunity Threshold (HIT) (the proportion of a population that needs to be immune in order for an infectious disease to become stable in that community)

$\mathrm{HIT}=1-1 / \mathrm{R}_{0}$

The incidence proportions, growth rates, doubling times and CFR were calculated on days 7, 14, 21 and 
28 from February till May 2020 (as only one case was reported prior to 28 February 2020). We used the median serial interval calculated by Nishiura H., et al. (2020) to calculate the basic reproductive number in Egypt (12). The median serial interval was estimated at 4.6 days.

\section{Results}

The COVID-19 epidemic curve looks flattened, although it indicates that Egypt is still in the rising phase of the epidemic (Figure 1). The first case in Egypt was recorded 15 February and the largest number of cases was recorded on 23 May (783). The daily number of deaths is also on the rise with little fluctuations over the specified time period. largest number of deaths was 29, recorded 25 May.

The epidemic growth rates and doubling time are shown in Figure 2. It reveals a steady and slow decline in the growth rates during the months of April and May when compared to rates in March. The highest level was in the first week of March (1.8). However, the shortest epidemic doubling time was during the first week of March, after which it gradually increased during April and May. The most recent data indicate that the number of cases will double every 15 days

Table 1 shows that there was a sharp increase in the weekly incidence proportion, starting in May, and reaching 14 cases / 100000 population. Additionally, there was a sudden increase in $\mathrm{R}_{0}$ in the period between 28 February and 7 March. $\mathrm{R}_{0}$ reached the highest value of 6.5 , when every infected person was able to transmit the infection to 6.5 persons.

As the epidemic progresses in Egypt, the $\mathrm{R}_{0}$ shows a steady and slow decline, reaching 1.6 during the third week of May. Herd Immunity Threshold (HIT) showed the same pattern as for the $\mathrm{R}_{0}$; the level was high in the early stages and declined to reach $39 \%$ by 21 May. This indicates that currently less than half of the Egyptian

Figure 1 Daily number of COVID-19 cases and deaths in Egypt

\# of cases

Daily number of cases

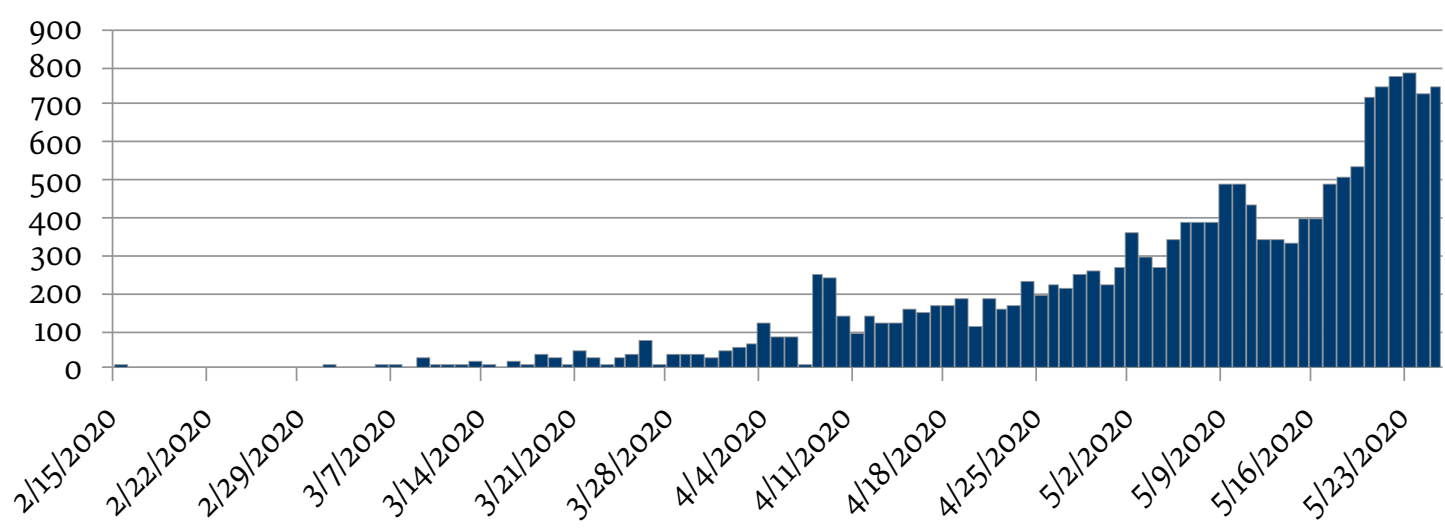

Date of onset of cases

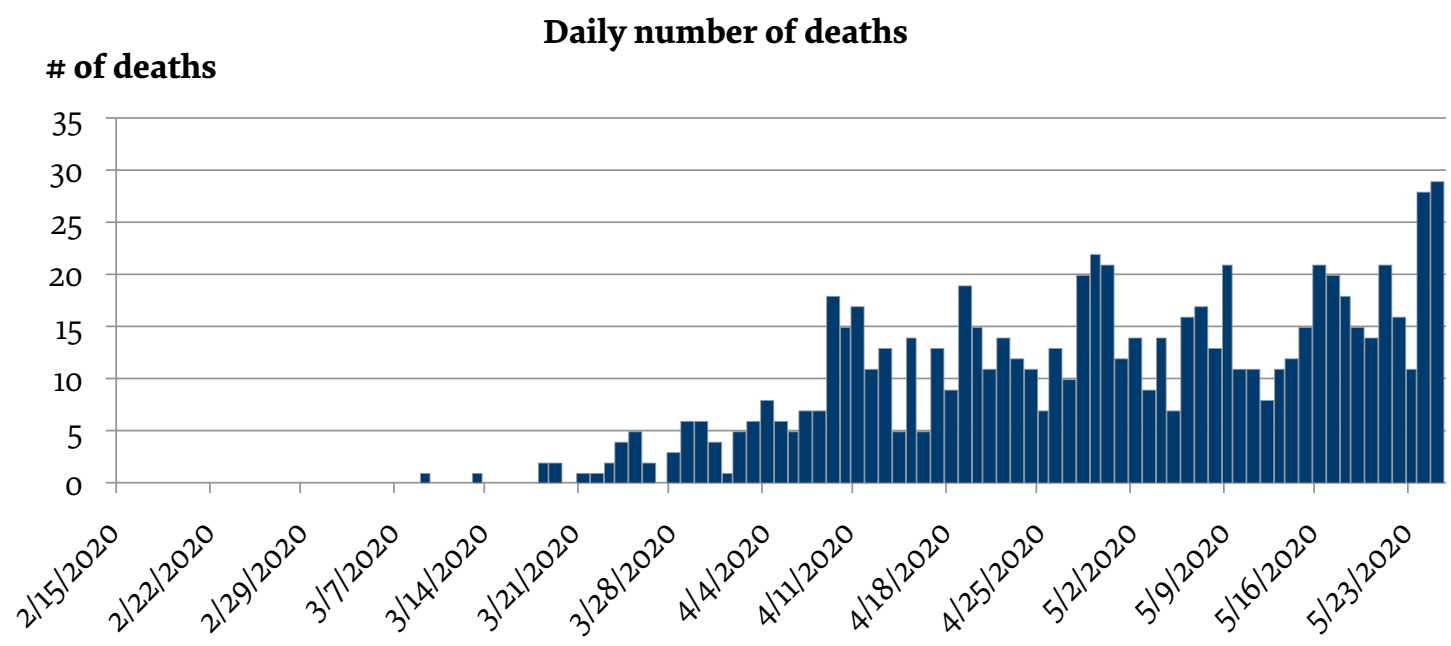

Date of reported deaths 


\section{Figure 2 Epidemic growth rate (r) and doubling time of COVID-19}

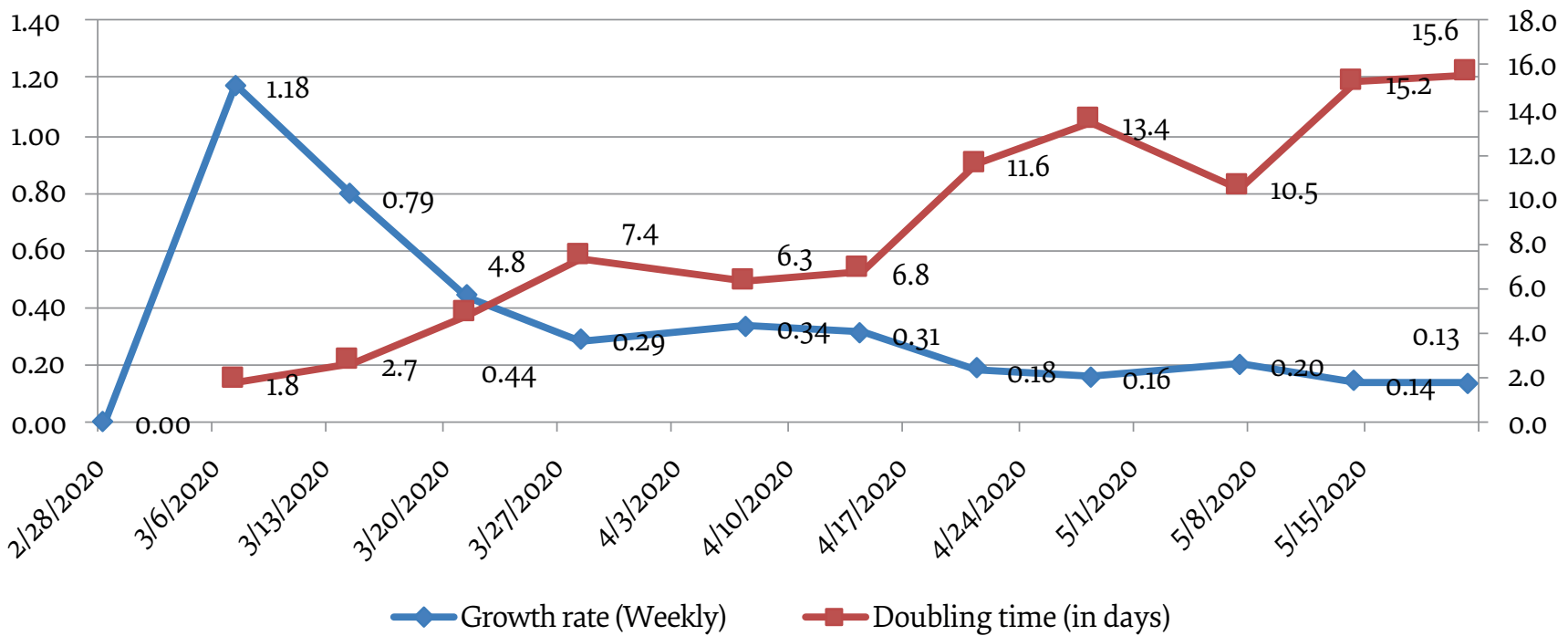

\begin{tabular}{|c|c|c|c|c|c|}
\hline Date & Incidence /100 000 & Growth rate & $\begin{array}{l}\text { Doubling time } \\
\text { (days) }\end{array}$ & $\mathbf{R}_{\mathrm{o}}$ & HIT (\%) \\
\hline $28 / 02 / 2020$ & 0 & 0 & & 1 & $0 \%$ \\
\hline 07/03/2020 & 0.02 & 1.18 & 1.8 & 6.5 & $85 \%$ \\
\hline $14 / 03 / 2020$ & 0.09 & 0.79 & 2.7 & 4.7 & $79 \%$ \\
\hline $21 / 03 / 2020$ & 0.26 & 0.44 & 4.8 & 3.1 & $67 \%$ \\
\hline $28 / 03 / 2020$ & 0.5 & 0.29 & 7.4 & 2.3 & $57 \%$ \\
\hline 07/04/2020 & 1.07 & 0.34 & 6.3 & 2.6 & $61 \%$ \\
\hline $14 / 04 / 2020$ & 2.19 & 0.31 & 6.8 & 2.5 & $59 \%$ \\
\hline $21 / 04 / 2020$ & 3.34 & 0.18 & 11.6 & 1.9 & $46 \%$ \\
\hline $28 / 04 / 2020$ & 4.79 & 0.16 & 13.4 & 1.7 & $42 \%$ \\
\hline 07/05/2020 & 7.6 & 0.2 & 10.5 & 1.9 & $49 \%$ \\
\hline $14 / 05 / 2020$ & 10.45 & 0.14 & 15.2 & 1.6 & $39 \%$ \\
\hline $21 / 05 / 2020$ & 14.25 & 0.13 & 15.6 & 1.6 & $39 \%$ \\
\hline Mean & 3.71 & 0.35 & 8.73 & 2.60 & $52 \%$ \\
\hline SD & 4.72 & 0.33 & 4.85 & 1.55 & $22 \%$ \\
\hline
\end{tabular}

population needs to be infected in order to halt the spread of COVID 19. The averages of the incidence proportion, growth rate, doubling time, $\mathrm{R}_{0}$ and HIT over the period from the first week of March until the third week of May were estimated to be 3.7/ 100 0oo, 0.35, 8.7 days, 2.6 and $52 \%$, respectively.

Finally, the case fatality rates has increased from $2.2 \%$ in the second week of March to reach its highest level after a 1-month period (7.5\%), following which there was a slow decline to reach the latest level of $4.8 \%$ (Figure 3 ).

\section{Discussion}

This study provided a summary description of the COVID-19 epidemic in Egypt, which can provide insights on future prevention and control measures planned to contain the epidemic, as well as the lockdown-exit strategies. Additionally, future data analysis using statistical time series methods can assist in the building of statistical models for COVID-19 epidemic forecasting.

Findings have confirmed the lockdown as an effective strategy to reduce the spread of COVID-19 in Egypt. This was demonstrated by the slow increase in the incidence proportion until mid-May, which was followed by a sharp increase coinciding with the relaxation of lockdown measures during the period of Ramadan. However, COVID-19 transmissibility is declining in Egypt and has currently reached its lowest level; $R_{0}$ value is 1.6. This implies that each infected person can transmit the infection to an average of 1.6 persons, which is consistent with previous studies (13). 


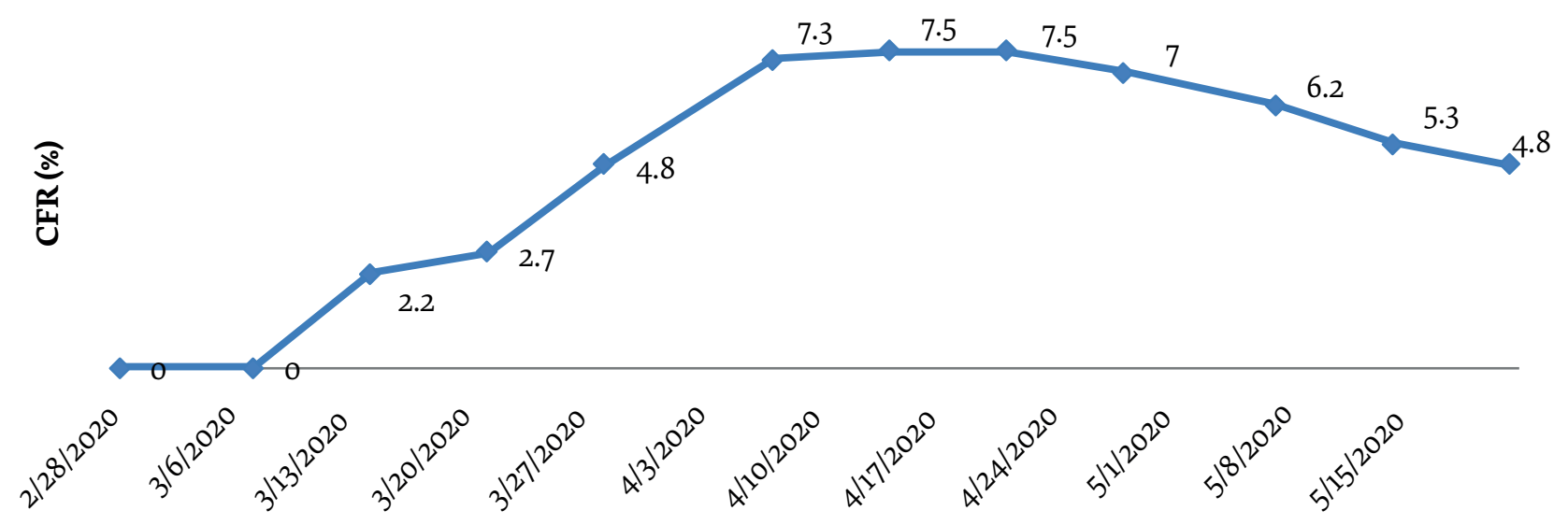

Date

CFR = case fatality rate

Reduced $\mathrm{R}_{\mathrm{o}}$ might be attributed to the increased compliance with physical distancing and other mitigation measures applied since March 2020. This notion is supported by the fact that the majority of models have shown that, in the absence of physical distancing, COVID-19 has a reproduction rate between 2 and 3 (or even higher rates). Furthermore, it was suggested that in absence of an effective vaccine, physical distancing measures combined with case-based interventions such as testing and contact tracing, are the key tools to lower the $\mathrm{R}_{\mathrm{o}}$ to levels below 1 (14).

Consistent with these findings are the results of the doubling time that have also witnessed an increase from values less than 2 days to the current level of over 15 days. An increase in the doubling time indicates a slowdown in transmission if the underlying reporting rate remains unchanged (6).

Given the assumption that COVID-19 infection gives long-lasting immunity, findings revealed that on average half of the Egyptian $n$ population needs to be immune to halt the spread of COVID-19. Kwok et al. (13) indicated that one likely source to novel SARS-CoV-2 partial immunity might be the presence of antibody cross-reactivity from previous infections with other common coronaviruses. They further attributed mild or asymptomatic infections to the same reason. In Egypt, limited screening and widespread testing hinders the accurate measurement of herd immunity levels, as well as evidence-informed decisions regarding the shift from community-wide interventions that focus on large populations to case-based interventions for prevention of COVID-19 (15).

In Egypt, the case fatality rate (CFR) increased from $2.2 \%$ during the second week of March to reach its highest level after a 1-month period (7.5\%), and then started to slowly decline to reach the latest level of $4.8 \%$. The sudden increase in case fatalities in the early stages of the epidemic in Egypt might be attributed to the 'censoring effect' - during the early epidemic stages, a substantial proportion of cases were still hospitalized and it was not known whether they would eventually recover or die from the disease. Therefore, in the method used to calculate CFR, these patients were included in the denominator but not in the numerator of the CFR, which lowers the early CFR estimates compared to later estimates of CFR. Furthermore, it is noteworthy to point out that CFR depends on the number of diagnosed cases, which in turn depends on the testing rates, which are currently low in Egypt and limited to suspected cases that seek medical care.

\section{Conclusion}

The notable decrease in the growth rate and $R_{0}$, as well as the increase in the doubling time of COVID-19, are indicative of reduced transmissibility and were most likely due to effective lockdown measures in Egypt. However, increasing incidence is an important criterion that should not been overlooked when governments decide to lift the lockdown measures. Reopening of businesses and sectors should be only considered when the number of new cases declines for 14 consecutive days; a condition that is not met in Egypt. Additional criteria for reopening should include testing capacity, health-care system preparedness, and public health capacity for contact tracing (14). Finally, lockdown-exit strategies should emphasize physical distancing and case-based interventions such as testing, contact tracing, and self-isolation for cases and contacts, in order to reduce COVID-19 transmission and prevent an uncontrolled upsurge of the epidemic $(14,16)$.

Funding: None.

Competing interests: None declared. 


\section{Épidémiologie du SARS-CoV-2 en Égypte}

\section{Résumé}

Contexte : Le 30 janvier 2020, l'Organisation mondiale de la Santé a déclaré que le nouveau coronavirus 2 du syndrome respiratoire aigu sévère constituait une urgence de santé publique de portée internationale. L'Égypte figure parmi les cinq pays notifiant le plus grand nombre de cas en Afrique.

Objectifs : Nous avions pour objectif de fournir un aperçu des caractéristiques épidémiques de la maladie à coronavirus (COVID-19) en Égypte afin d'aider à orienter une stratégie efficace de confinement-déconfinement.

Méthodes : Les chiffres de l'incidence, les taux de létalité, les taux de croissance, le temps de doublement, le taux de reproduction de base $\left(R_{0}\right)$ et le seuil d'immunité collective ont été calculés et revus chaque semaine.

Résultats : Au 21 mai 2020, le taux de croissance épidémique et le $\mathrm{R}_{0}$ ont nettement diminué ; les moyennes ( $\pm \mathrm{ET}$ ) étaient respectivement de 0,35 $( \pm 0,33)$ et de 2,6 $( \pm 1,55)$. Toutefois, l'incidence a augmenté, passant à 14 cas pour 100000 habitants.

Conclusion : La transmissibilité de la COVID-19 a diminué mais l'incidence a augmenté, soulignant que toute stratégie de confinement-déconfinement devrait inclure des mesures pour renforcer la distanciation physique et des interventions basées sur les cas pour prévenir une recrudescence non contrôlée des cas de COVID-19.

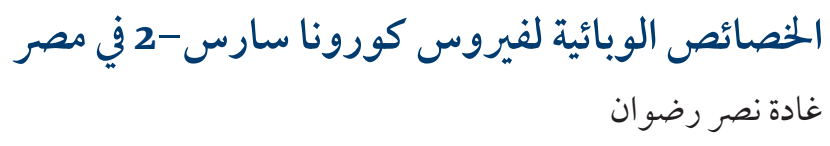

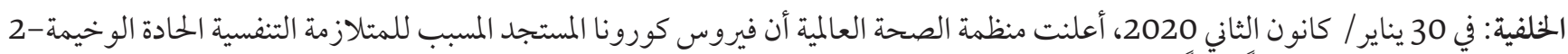

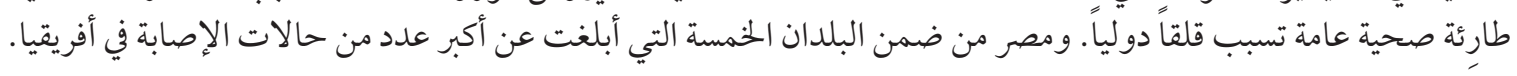

الأهداف: هدفت هذه الدر اسة إلى تقديم نبذة عامة عن الخصائص الوبائية لمرض كوفيد-19 في مصر من أجل المساعدة على توجيه استراتيجية فعالة اللخروج من الخظر.

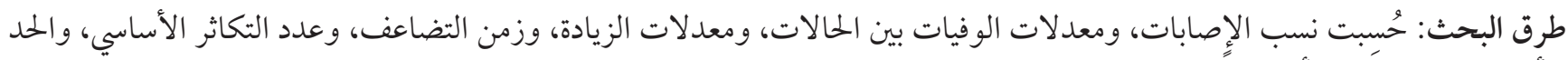

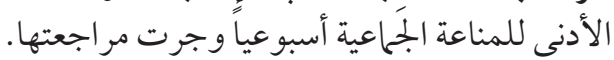

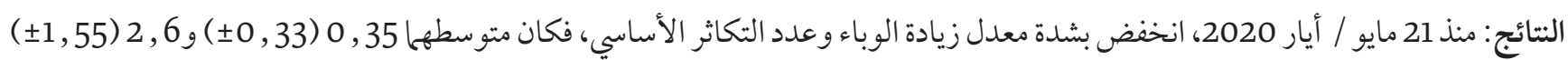

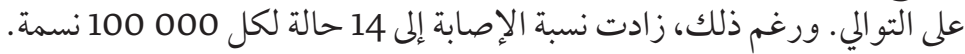

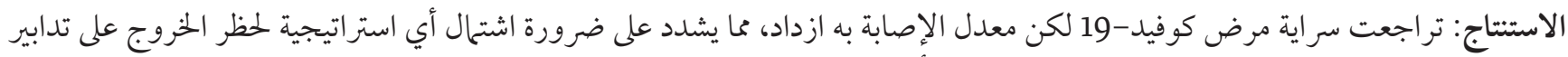

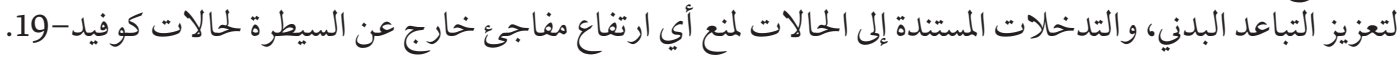

\section{References}

1. Rothan HA, Byrareddy SN. The epidemiology and pathogenesis of coronavirus disease (COVID-19) outbreak. J Autoimmun. 2020;109:102433.

2. Ciotti M, Angeletti S, Minieri M, Giovannetti M, Benvenuto D, Pascarella S, et al. COVID-19 Outbreak: An Overview. Chemotherapy. 2020:1-9.

3. European Centre for Disease Prevention and Control. COVID-19 situation update worldwide, as of 25 May 2020 [Internet]. 2020 (https://www.ecdc.europa.eu/en/geographical-distribution-2019-ncov-cases).

4. European Centre for Disease Prevention and Control. Q \& A on COVID-19 [Internet]. 2020. (https://www.ecdc.europa.eu/en/covid-19/questions-answers).

5. Liu Y, Gayle AA, Wilder-Smith A, Rocklov J. The reproductive number of COVID-19 is higher compared to SARS coronavirus. J Travel Med. 2020;27(2).

6. Muniz-Rodriguez K, Chowell G, Cheung CH, Jia D, Lai PY, Lee Y, et al. Doubling Time of the COVID-19 Epidemic by Province, China. Emerg Infect Dis. 2020;26(8).

7. Bein B, Bachmann M, Huggett S, Wegermann P. [SARS CoV-2/COVID-19: Evidence-Based Recommendation on Diagnosis and Therapy]. Anasthesiol Intensivmed Notfallmed Schmerzther. 2020;55(4):257-65.

8. Guo YR, Cao QD, Hong ZS, Tan YY, Chen SD, Jin HJ, et al. The origin, transmission and clinical therapies on coronavirus disease 2019 (COVID-19) outbreak - an update on the status. Mil Med Res. 2020;7(1):11.

9. Presidency of the Council of Ministers: COVID 19 update in Egypt. [Internet]. 2020. (https://www.care.gov.eg/EgyptCare/Index. aspx). 
10. Coursera TUoHKa. Epidemics Course. 2020. (https://www.coursera.org/learn/hkuepidemics/home/welcome).

11. Centers for Disease Control and Prevention. Principles of epidemiology in public health practice [Internet]. 2020. (https://www. cdc.gov/csels/dsepd/ss1978/lesson3/section2.html).

12. Nishiura H, Linton NM, Akhmetzhanov AR. Serial interval of novel coronavirus (COVID-19) infections. Int J Infect Dis. 2020;93:284-6.

13. Kwok KO, Lai F, Wei WI, Wong SYS, Tang JWT. Herd immunity - estimating the level required to halt the COVID-19 epidemics in affected countries. J Infect. 2020;80(6):e32-e3.

14. Public health principles for a phased reopening during COVID-19: guidance for governors [Internet]. The Johns Hopkins Center for Health Security. 2020. (https://www.centerforhealthsecurity.org/our-work/publications/public-health-principles-for-aphased-reopening-during-covid-19-guidance-for-governors).

15. American Enterprise Institute. Report: National coronavirus response: a road map to reopening [Internet]. 2020. (https://www. aei.org/research-products/report/national-coronavirus-response-a-road-map-to-reopening/).

16. World Health Organization. WHO COVID 19 strategy update - 14 April 2020. Geneva: World Health ORganization; 2020 (https:// www.who.int/publications-detail/covid-19-strategy-update---14-april-2020). 